\title{
Carvão de resíduos de indústria madeireira de três espécies florestais exploradas no município de Paragominas, $\mathbf{P A}^{1}$
}

\author{
Marcela Gomes da SILVA², Sueo NUMAZAWA33, Maristela Machado ARAUJO ${ }^{4}$, Thais Yuri Rodrigues \\ NAGAISHI $^{5}$, Gilvana Rodrigues GALVÃO ${ }^{6}$
}

\begin{abstract}
RESUMO
Este trabalho avalia as principais propriedades do carvão de Manilkara amazonica (maçaranduba), Lecythis pisonis (sapucaia) e Piptadenia suaveolens (timborana), carbonizadas em sete e dez dias. O carvão foi produzido a partir de resíduos da serraria da Empresa Cikel Brasil Verde S. A., na Fazenda Rio Capim, em Paragominas. Foram utilizados 30 fornos de alvenaria, sendo dez fornos para cada espécie, dos quais cinco para carbonização em sete dias e cinco para dez dias. Após a carbonização, foram retiradas amostras de carvão produzido para estudo de rendimento gravimétrico e de propriedades físicas, químicas e mecânicas. Os principais resultados foram: o rendimento gravimétrico do carvão variou de 21,47 a 29,59\% (base úmida); a densidade média a granel, variou de 178,51 a $231,14 \mathrm{~kg} \cdot \mathrm{m}^{-3}$; a densidade média aparente foi de 0,38 a $0,53 \mathrm{~g} \cdot \mathrm{cm}^{-3}$; o poder calorífico foi de $23451 \mathrm{a} 28830 \mathrm{kj}^{-\mathrm{kg}^{-1}}$; o teor de materiais voláteis variou de 23,94 a 31,47\%; cinzas de 0,7 a 2,5\%; o carbono fixo de 68,29 a 74,49\%; e a friabilidade de 12 a $32,6 \%$. Constatou-se que a espécie é o principal fator que influencia nas propriedades do carvão. Através da análise das propriedades, não foi possível identificar qual espécie produziu o melhor carvão, uma vez que as três apresentaram algumas características consideradas boas, porém, sempre acompanhadas de outras inadequadas.
\end{abstract}

\section{PALAVRAS-CHAVE}

Carvão vegetal, Manilkara amazônica, Lecythis pisonis, Piptadenia suaveolens, propriedades do carvão.

\section{Charcoal from timber industry residues of three tree species logged in the municipality of Paragominas, PA}

\begin{abstract}
The timber industry in Amazonia generates large quantities of residues from log processing. A viable alternative for the enterprises is the production of charcoal from these residues. This study evaluates the main properties of the charcoal from Manilkara amazonica (maçaranduba), Lecythis pisonis (sapucaia) and Piptadenia suaveolens (timborana), carbonized in 7 and 10 days. The charcoal was produced from residues of timbers from the sawmill of Cikel Brasil Verde S. A., in Rio Capim estate, Paragominas, PA. A series of 30 kilns was used, being 10 for each species, of which 5 kilns used a 7-day carbonization process and 5 kilns 10 days. After the carbonization, samples of the charcoal produced were collected for studying gravimetric yield and physical, chemical and mechanical properties. The main results were: gravimetrical yield of the charcoal varied from 21,47 to 29,59\% (humid base); the bulk medium density varied from 178,51 to 231,14 kg. $\mathrm{m}^{-3}$; apparent medium density from 0,38 to 0,53 g.cm $\mathrm{cm}^{-3}$; calorific power from 23451 to $28830 \mathrm{kj} \cdot \mathrm{kg}^{-1}$; volatile materials content from 23,94 to 31,47\%; ashes from 0,7 to 2,5\%; fixed carbon from 68,29 to 74,49\%; and the friableness varied from 12 to 32,6\%. It was noted that species is the main factor that influences the properties of the charcoal. It was not possible to say which species produced the best charcoal, from the properties analyses, because all the three species present some good characteristics, but these are always accompanied by other inadequate characteristics.
\end{abstract}

\section{KEY-WORDS}

Charcoal, Manilkara amazonica, Lecythis pisonis, Piptadenia suaveolens, properties of the charcoal.

\footnotetext{
${ }^{7}$ Trabalho desenvolvido através do Programa de Pós-Graduação em Ciências Florestais da Universidade Federal Rural da Amazônia - UFRA, com apoio da Cikel Brasil Verde S.A. ${ }_{2}^{2}$ Professora, UFRA/ Tapajós, Santarém, PA. e-mail: marcela.gsilva@gmail.com

${ }_{3}^{3}$ Professor no Departamento de Química e Tecnologia da Madeira, UFRA, PA. E-mail: sueonuma@yahoo.com.br

${ }^{4}$ Professora na Universidade Federal de Santa Maria, UFSM, RS. E-mail: araujo.maristela@gmail.com

${ }^{5}$ Aluna do Curso de Mestrado em Ciências Florestais da UFRA, PA. E-mail: florestal@oi.com.br

${ }^{6}$ Laboratório de Tecnologia e Produtos Florestais da UFRA, PA. E-mail: gilvanagalvao@yahoo.com.br
} 


\section{INTRODUÇÃo}

A madeira ainda é o produto mais comercializado da floresta. Para exploração da madeira em regiōes de mata nativa, torna-se necessária a aplicação do manejo sustentado de florestas, mantendo, com isto, o equilíbrio ecológico. A utilização racional e eficiente dos recursos de biomassa, mediante o emprego de tecnologias modernas e a utilização de resíduos, é uma alternativa viável (Benzo \& Luengo, 1998).

Dentre os produtos derivados da madeira, o carvão tem uma posição de destaque na geração de energia. A utilização da biomassa vegetal para fins energéticos deve ser considerada como alternativa de utilização dos recursos naturais existentes, sendo que a maioria da matéria-prima, para esse fim, é oriunda de florestas naturais.

A conversão integral de uma floresta tropical densa exclusivamente em carvão vegetal não seria admissível, tendo-se em vista a ocorrência de espécies de madeira para uso mais nobre. Seria justificado, sim, o aproveitamento de fontes disponíveis como madeiras remanescentes de exploração florestal, de resíduos industriais, entre outras (Numazawa, 1986).

Atualmente, a produção de energia é uma necessidade incontestável, pois a busca por combustível, tanto no meio rural como no urbano, é crescente e tem levado à procura por energias alternativas, como o carvão vegetal, que além de ser um produto derivado de matéria-prima renovável, também pode ser utilizado como redutor de minérios em indústrias siderúrgicas, usinas termoelétricas e indústrias químicas.

A produção de carvão vegetal no Brasil é de significativa importância econômica e se desenvolve basicamente de duas maneiras: tradicional, empregando lenha de floresta nativa, cortada para transformação em áreas agrícolas; e moderna, carbonizando lenha de floresta plantada (Nogueira \& Lora, 2003).

As propriedades do carvão vegetal estão intimamente ligadas aos parâmetros do processo de produção e da matéria-prima que lhe deu origem. Existem várias pesquisas realizadas sobre o processo de produção de carvão vegetal, porém apenas em níveis laboratoriais e com espécies exóticas, principalmente eucalipto e pinus. Há, portanto, a necessidade de se buscar conhecimentos sobre o comportamento na carbonização de resíduos de espécies nativas da região amazônica, assim como sobre os métodos de controle de qualidade, em campo, permitindo assim caracterizar as propriedades do carvão vegetal, oriundo de resíduos de exploração florestal e resíduo de indústrias madeireiras, considerando o grande desperdício dos mesmos.

Considerando estes aspectos, o presente trabalho teve como objetivo geral estudar as características físicas (densidade e poder calorífico), químicas (teores de materiais voláteis, cinzas e carbono fixo) e mecânicas (friabilidade) do carvão de resíduo de madeira das espécies maçaranduba, sapucaia e timborana, produzido em diferentes tempos de carbonização.
Este estudo vai possibilitar a empresa direcionar a sua produção de carvão, conforme a espécie e qualidade do produto gerado, de acordo com as necessidades da demanda industrial.

\section{MATERIAL E MÉTODOS}

\section{ÁREA DE ESTUDO}

O material estudado originou-se da Fazenda Rio Capim, de propriedade da Empresa Cikel Brasil Verde S.A., localizada no município de Paragominas, distante cerca de $320 \mathrm{~km}$ de Belém, PA, entre as coordenadas geográficas 3 $30^{\prime}$ e 3o 45' de latitude sul e $48^{\circ} 30^{\prime}$ e $48^{\circ} 45^{\prime}$ de longitude a oeste de Greenwich. O município de Paragominas está localizado no nordeste do Estado do Pará, na microrregião homogênea Guajarina (Watrin \& Rocha, 1991).

Aárea é caracterizada por possuir períodos de elevados índices de chuva, $250 \mathrm{~mm}$ mensais, e períodos de baixos índices (SUDAM/EMBRAPA, 1993). O período chuvoso tem início em novembro/dezembro, prolongando-se a março/abril com precipitação pluviométrica anual de 1.800 a $2.100 \mathrm{~mm}$. A temperatura média anual é de $27^{\circ} \mathrm{C}$. A umidade relativa do ar é alta, com valores entre 80 e $85 \%$. Segundo a classificação de Köeppen, o clima dominante na região é do tipo "Awi”.

A vegetação natural da região foi classificada, de acordo com Veloso et al. (1991), em Floresta Ombrófila Densa Submontana, Floresta Ombrófila Densa de terras Baixas e Floresta Ombrófila Densa Aluvial.

\section{SELEÇÃO DAS ESPÉCIES}

Para este estudo foram selecionadas as espécies Manilkara amazonica (Huber) A.Chev. (maçaranduba), Lecythis pisonis Cambess. (sapucaia) e Piptadenia suaveolens Miq. (timborana), tomando-se como base a maior disponibilidade de resíduos na indústria no período em que se desenvolveu o trabalho, além de serem espécies freqüentes na floresta da fazenda.

\section{DETERMINAÇÃO DA DENSIDADE BÁSICA DA MADEIRA}

Do lote de resíduos de cada espécie selecionada foram coletadas, aleatoriamente, 20 amostras de madeira de cada fornada, num total de 200 (duzentas) unidades, as quais foram enviadas ao Laboratório de Tecnologia de Produtos Florestais (LTPF) da Universidade Federal Rural da Amazônia (UFRA), em Belém, onde foram preparados 20 corpos de prova de cada amostra coletada com dimensão de $2 \times 2 \times 3 \mathrm{~cm}$.

A densidade da madeira foi determinada com base na Norma MB 1269/79 da Associação Nacional de Normas Técnicas ABNT, através da equação 1 :

$$
\rho=\frac{P o}{V_{(s a t)}}
$$


Considerando que,

$\rho=$ densidade básica $\left(\mathrm{g} \cdot \mathrm{cm}^{-3}\right)$.

Po = peso do corpo de prova absolutamente seco $(\mathrm{g})$.

$\mathrm{V}_{\text {(sat) }}$ = volume do corpo de prova saturado $\left(\mathrm{cm}^{3}\right)$.

A saturação dos corpos de prova foi realizada, submergindo a madeira em água destilada dentro de um dessecador acoplado a uma bomba a vácuo. A completa saturação foi alcançada no momento em que o peso do corpo de prova não sofreu mais variação em três pesagens consecutivas.

O volume do corpo saturado foi determinado através do método de pesagem baseado no princípio de Arquimedes, recomendado pela Comissão Panamericana de Normas TécnicasCOPANT 461.

Após a determinação do volume saturado do corpo de prova, este foi submetido à secagem em uma estufa com $103 \pm 2^{\circ} \mathrm{C}$ até atingir a estabilização do peso em três pesagens consecutivas, condição em que caracteriza a ausência completa de água na parede celular, correspondente ao peso do corpo de prova absolutamente seco ( $0 \%$ de umidade).

\section{CARBONIZAÇÃO DOS RESÍDUOS DE MADEIRA}

A carbonização foi realizada em fornos de alvenaria tipo "Rabo Quente", utilizados pela empresa, com capacidade volumétrica nominal de $16 \mathrm{~m}^{3}$, adotando-se a técnica tradicional de carbonização empregada pela empresa. Foram utilizados dez fornos para cada espécie, sendo cinco para um ciclo de carbonização de sete dias e outros cinco para um ciclo de dez dias. Para estimar o peso do carvão produzido foi contado o número de balaios cheios de carvão. Em seguida determinou-se a média do peso de cinco balaios para, então, calcular o peso total de carvão obtido por fornada.

Para os estudos de caracterização das propriedades do carvão, coletou-se em um saco de $60 \mathrm{~kg}$ a amostra de carvão de cada fornada, que foram encaminhadas ao Laboratório de Tecnologia de Produtos Florestais da UFRA, onde foram realizados os testes.

\section{DETERMINAÇÃO DE RENDIMENTO GRAVIMÉTRICO}

O rendimento gravimétrico consistiu na relação entre o peso do carvão produzido e o peso da madeira enfornada, expresso em porcentagem e calculado através da equação 2 .

$$
R G c=\frac{P_{\text {carvão }}}{P_{\text {madeira }}} x 100
$$

Considerando que,

$\mathrm{RGc}=$ rendimento gravimétrico de carvão (\%).

$\mathrm{P}_{\text {carvão }}=$ peso do carvão produzido $(\mathrm{kg})$.

$\mathrm{P}_{\text {madeira }}=$ peso da madeira enfornada $(\mathrm{kg})$.
O peso do carvão foi obtido com base no número de balaios e o peso médio de cinco balaios cheios de carvão. $\mathrm{O}$ peso da madeira enfornada foi obtido com base no produto entre o volume nominal do forno e a densidade média da madeira.

Portanto, o rendimento é um valor que foi calculado apenas como referência teórica, mas que expressa a relação entre o produto sólido formado (carvão) e a madeira enfornada.

\section{CARACTERIZAÇÃO DAS PROPRIEDADES DO CARVÃO}

Foi feita a caracterização das propriedades físicas, químicas e mecânica (friabilidade) do carvão vegetal.

\section{PROPRIEDADES FÍSICAS}

\section{DENSIDADE A GRANEL}

A densidade a granel expressa o peso dos pedaços de carvão contidos em um recipiente de $1 \mathrm{~m}^{3}$ de volume. Neste estudo utilizou-se um balaio com capacidade em torno de $0,2 \mathrm{~m}^{3}$. De cada fornada, foram tomadas amostras de carvão para encher cinco balaios que foram pesados em uma balança com capacidade de $100 \mathrm{~kg}$. A densidade a granel foi calculada através da equação 3.

$$
D_{\text {gran. }}=\frac{P_{\text {carvão }}}{V_{\text {recip. }}}
$$

Considerando que,

Dgran.$=$ Densidade a granel do carvão $\left(\mathrm{g} . \mathrm{cm}^{-3}\right)$.

$P$ carvão $=$ Peso do carvão $(\mathrm{kg})$.

Vrecip. $=$ Volume do recipiente $\left(\mathrm{m}^{3}\right)$.

\section{DENSIDADE APARENTE DO CARVÃO}

Das amostras de carvão coletadas de cada fornada foram preparados dez corpos de prova para determinação da densidade básica, adaptando-se a Norma MB 1269/79 da ABNT, através da equação 4 .

$$
D_{(\text {ap.c. })}=\frac{P_{(\text {c.s. })}}{V_{(\text {c.sat })}}
$$

Considerando que,

$D$ (ap.c.) $=$ Densidade aparente do carvão $\left(\mathrm{g} . \mathrm{cm}^{-3}\right)$.

$P$ (c.s.) $=$ Peso do carvão seco (g).

$V($ c.sat. $) \quad=$ Volume do carvão saturado $\left(\mathrm{g} . \mathrm{cm}^{-3}\right)$.

$\mathrm{O}$ peso e o volume do carvão foram determinados com o mesmo método da determinação da densidade básica da madeira. 


\section{PODER CALORIFICO DO CARVÃO}

Adotou-se a Norma D5865-04 da "American Society for Testing and Material" - ASTM (2005), para determinar o poder calorífico superior do carvão. Foram utilizadas três amostras de cada fornada; e o poder calorífico foi determinado em uma bomba calorimétrica adiabática, pelo método de Berttelot, que consiste na combustão do material em um ambiente fechado, na presença de oxigênio e sob pressão.

\section{PROPRIEDADES QUIIMICAS}

\section{ANÁLISES QUÍMICAS IMEDIATAS DO CARVÃO}

As análises químicas do carvão vegetal se referem à determinação da porcentagem dos teores de materiais voláteis (TMV), de cinzas (Tci) e de carbono fixo (TCF) contidos no carvão, com base na Norma D1762/64 da ASTM.

O material utilizado foi codificado por fornada, transformado em partículas utilizando-se um gral e o carvão foi classificado granulometricamente entre 24 e 32 mesh. Geralmente essas partículas são obtidas por meio de processo mecânico.

\section{TEOR DE MATERIAIS VOLÁTEIS}

Foram utilizados três cadinhos com tampas para cada amostra de carvão, anotando-se o peso dos mesmos: $\mathrm{P}_{(\mathrm{cad} 1)}, \mathrm{P}_{(\mathrm{cad} 2)}, \mathrm{P}_{(\mathrm{cad} 3)}$. Em seguida, pesou-se cerca de 3 gramas de carvão moído e peneirado em peneiras de 24 e 32 mesh, submetendo, posteriormente, à calcinação em um forno mufla a $950^{\circ} \mathrm{C}$, durante 6 minutos. O teor de materiais voláteis foi determinado através da equação 5 .

$$
T M V=\left(\frac{P_{(c . s)}-P_{(c . c a l .)}}{P_{(c . s .)}}\right) x 100
$$

Considerando que,

$T M V=$ Teor de materiais voláteis (\%).

$P($ c.s. $)=$ Peso das partículas de carvão seco em estufa a $103^{\circ} \pm 2$ ${ }^{\circ} \mathrm{C}(\mathrm{g})$.

$P($ c.cal. $)=$ Peso das partículas de carvão calcinado a $950^{\circ} \mathrm{C}$ durante 6 minutos $(\mathrm{g})$

\section{TEOR DE CINZAS}

Forma utilizados três cadinhos sem tampas, os quais foram pesados em uma balança analítica, registrando-se seus pesos de $\mathrm{P}_{\text {(cad1) }}, \mathrm{P}_{\text {(cad2) }}, \mathrm{P}_{\text {(cad3). }}$ Posteriormente, foram pesados em cada cadinho cerca de dois gramas das amostras de carvão moído, com a mesma granulometria do carvão utilizado para materiais voláteis. Em seguida, os cadinhos sem tampa foram submetidos à combustão completa sob temperatura de $750{ }^{\circ} \mathrm{C}$ durante 6 horas, e o teor de cinzas foi calculado através da equação 6 .

$$
T C i=\frac{P_{(c i .)}}{P_{(c . s .)}} \times 100
$$

Considerando que,

$T c i=$ Teor de cinzas (\%).

$P(c i)=$. Peso do material incinerado (cinzas) a $750^{\circ} \mathrm{C}$ durante 6 horas $(\mathrm{g})$.

\section{TEOR DE CARBONO FIXO}

A partir da obtenção de materiais voláteis e de cinza, o teor de carbono fixo foi determinado indiretamente através da equação 7.

$$
T C F=100-(T M V+T C i)
$$

Considerando que,

$T C F=$ Teor de carbono fixo (\%).

$T M V=$ Teor de materiais voláteis (\%).

$T C i=$ Teor de cinzas $(\%)$.

\section{PROPRIEDADE MECÂNICA}

A propriedade mecânica do carvão (friabilidade) consiste na resistência do mesmo para se transformar em partículas e pó, devido ao seu manuseio (descarregamento, embalagem e transporte). É determinada através do teste de tamboramento, de acordo com a Norma MB 1375/80 da ABNT.

Foram utilizadas amostras aleatórias de carvão, passadas em uma peneira com malha de $5 \times 5 \mathrm{~cm}$ de seção transversal e retida em malha de $2 \times 2 \mathrm{~cm}$. O comprimento do carvão variou de $5 \mathrm{a}$ $10 \mathrm{~cm}$. Para o teste de friabilidade, utilizou-se cerca de $500 \mathrm{~g} \mathrm{de}$ carvão, correspondendo ao peso inicial do carvão (Pi). Posteriormente, as amostras foram submetidas a choque e atrito a $30 \mathrm{rpm}$, em um tambor, por dez minutos. Após o tamboramento, todo o carvão retido na peneira com malha de $2 \times 2 \mathrm{~cm}$, foi pesado, correspondendo ao peso do carvão remanescente $(\mathrm{Pr})$; e a friabilidade foi calculada através da equação 8 .

$$
F=\frac{P_{i}-P_{(r)}}{P_{(i)}} \times 100
$$

Considerando que,

F - Friabilidade do carvão (\%).

$\mathrm{P}_{\mathrm{r}}$ - Peso do carvão remanescente após o tamboramento $(\mathrm{g})$.

$\mathrm{P}_{\mathrm{i}}$ - Peso inicial do carvão $(\mathrm{g})$.

\section{ANÁLISE ESTATÍSTICA}

Considerando a utilização de delineamento completamente casualizado, realizou-se a análise estatística através de tratamentos fatoriais $3 \times 2$, conforme indicados na Tabela 1 , sendo que as repetições corresponderam aos cinco fornos utilizados no estudo. 
Tabela 1 - Fatores e níveis adotados para as análises estatísticas de três espécies madeireiras carbonizadas em sete e dez dias. Cikel Brasil Verde S.A./ Universidade Federal Rural da Amazônia.

\begin{tabular}{ccc}
\hline Fator & Nível & Especificação \\
\hline & $a_{0}$ & maçaranduba - Manilkara amazonica (Huber) A. Chev. \\
A (espécie) & $a_{1}$ & sapucaia - Lecythis pisonis Cambess. \\
& $\mathrm{a}_{2}$ & timborana - Piptadenia suaveolens Miq. \\
B (tempo de & $\mathrm{b}_{0}$ & Sete dias \\
carbonização) & $\mathrm{b}_{1}$ & Dez dias \\
\hline
\end{tabular}

Primeiramente, foram feitos estudos de homogeneidade de variância pelo teste de Cochran e de normalidade na distribuição dos dados pelo teste de Lilliefors. Após a verificação desses parâmetros, então, realizou-se a análise de variância e o teste de significância pelo método de SNK ao nível de 5\% de probabilidade.

\section{RESULTADOS E DISCUSSÃO}

Os resultados de rendimento gravimétrico, densidade aparente, teor de materiais voláteis, cinzas e carbono fixo do carvão, apresentaram homogeneidade da variância e normalidade dos dados, o que permitiu análise de variância, com tratamentos fatoriais. A densidade a granel, poder calorífico e friabilidade tiveram seus valores transformados por logarítmo neperiano, quando então foi possível satisfazer as condiçôes básicas para tal análise.

\section{DENSIDADE BÁSICA DA MADEIRA}

Nos testes de densidade básica da madeira, observou-se que a maçaranduba apresentou densidade média de 0,86 $\pm 0,02$ g. $\mathrm{cm}^{-3}$, sapucaia $0,91 \pm 0,01 \mathrm{~g} . \mathrm{cm}^{-3}$, e timborana $0,75 \pm 0,06$ g. $\mathrm{cm}^{-3}$. Os resultados obtidos estão dentro ou próximos dos limites dos encontrados na literatura. Por exemplo, Souza et al. (1997) encontraram para maçaranduba $0,83 \mathrm{~g} . \mathrm{cm}^{-3}$, timborana $0,76 \mathrm{~g} \cdot \mathrm{cm}^{-3}$ e sapucaia $0,84 \mathrm{~g} \cdot \mathrm{cm}^{-3} ; \operatorname{IBDF}(1988)$ registrou 0,89 a $0,93 \mathrm{~g} \cdot \mathrm{cm}^{-3}$ e Aquino (2003) $0,91 \mathrm{~g} \cdot \mathrm{cm}^{-3}$ para madeira de maçaranduba.

Tais variações entre os estudos são explicadas por Harris (1965), quando cita que as diferentes densidades para uma mesma espécie variam conforme a procedência do material e a variação entre árvores na própria área. Este aspecto é importante para a produção de carvão, considerando que a densidade da madeira tem relação direta com a densidade do carvão.

As madeiras de maçaranduba e sapucaia, de acordo com Souza et al. (1997), são consideradas madeiras pesadas enquanto que timborana é classificada como madeira de densidade média.

\section{RENDIMENTO GRAVIMÉTRICO DO CARVÃO VEGETAL}

$\mathrm{Na}$ Tabela 2, encontram-se os valores de rendimento em carvão das três espécies estudadas. Constata-se uma variação de rendimento entre 21,47 e 29,55\%. À exceção do rendimento em carvão obtido com a madeira de timborana carbonizada em sete dias, que apresentou rendimento de $29,55 \%$, os demais foram inferiores aos de Pastore et al. (1989) que encontraram, em escala laboratorial, entre $27 \%$ e $37 \%$ com vinte espécies da Amazônia.

Outros autores como Oliveira et al. (1989) e Vale et al. (1997), ao estudarem o Eucalyptus grandis, espécie mais utilizada como matérias-primas para carvão vegetal, encontraram valores de $35 \%$ e 33\%, respectivamente, bem acima dos que foram encontrados neste trabalho. Porém, isto é compreensível, uma vez que os estudos realizados por esses autores foram todos em escala laboratorial e calculados à base seca, enquanto que neste estudo, os resultados estão expressos à base úmida e o carvão foi produzido em escala industrial, obedecendo exatamente à técnica empregada pelo produtor.

Em relação ao tempo de carbonização, esperava-se que no ciclo de dez dias resultasse em menor rendimento, uma vez que uma maior exposição ao processo pirolítico significa um maior grau de volatilização. No entanto, no caso das espécies maçaranduba e sapucaia, os resultados não mostraram essa tendência, somente a timborana seguiu esse comportamento.

No caso das duas espécies que praticamente não apresentaram variação no rendimento, pressupōe-se que o teor de umidade tenha sido um fator que influenciou nos resultados obtidos, ou seja, as madeiras foram carbonizadas sem estarem com o teor de umidade homogêneo.

No ciclo de carbonização de dez dias, possivelmente, os resíduos foram encontrados com um maior grau de umidade, necessitando-se de um maior tempo para secagem da madeira e, conseqüentemente, retardando as reações pirolíticas. Essa argumentação está exatamente em consonância com a afirmação

Tabela 2 - Porcentagem média de rendimento gravimétrico (RG), densidade a granel (DG), densidade aparente (DA), poder caloríico (PC), materiais voláteis (MV), teor de cinzas (TC), carbono fixo (CF), friabilidade (F) em carvão de três espécies madeireiras carbonizadas, em 7 e 10 dias. Cikel Brasil Verde S.A./ Universidade Federal Rural da Amazônia.

\begin{tabular}{|c|c|c|c|c|c|c|c|c|c|c|c|c|c|c|c|c|}
\hline \multirow[b]{2}{*}{ ESPÉCIE } & \multicolumn{2}{|c|}{ RG (\%) } & \multicolumn{2}{|c|}{$\mathrm{DG}\left(\mathrm{kg} \cdot \mathrm{m}^{-3}\right)$} & \multicolumn{2}{|c|}{$\mathrm{DA}\left(\mathrm{g} . \mathrm{cm}^{-3}\right)$} & \multicolumn{2}{|c|}{ PC (kj. $\left.\mathrm{Kg}^{-1}\right)$} & \multicolumn{2}{|c|}{ MV (\%) } & \multicolumn{2}{|c|}{ TC (\%) } & \multicolumn{2}{|c|}{ CF (\%) } & \multicolumn{2}{|c|}{$\mathbf{F}(\%)$} \\
\hline & 7 & 10 & 7 & 10 & 7 & 10 & 7 & 10 & 7 & 10 & 7 & 10 & 7 & 10 & 7 & 10 \\
\hline Maçaranduba & 25,37 & 25,68 & 231,1 & 231,1 & 0,55 & 0,52 & 26841 & 23451 & 24,71 & 27,93 & 0,8 & 0,7 & 74,49 & 71,35 & 26,60 & 32,60 \\
\hline Sapucaia & 21,47 & 21,59 & 210,0 & 195,5 & 0,56 & 0,49 & 27539 & 28830 & 26,00 & 23,94 & 1,3 & 2,5 & 72,66 & 73,58 & 30,20 & 27,60 \\
\hline Timborana & 29,55 & 25,70 & 176,7 & 180,5 & 0,38 & 0,39 & 27444 & 26041 & 24,44 & 31,47 & 1,5 & 1,4 & 74,02 & 68,29 & 12,00 & 14,67 \\
\hline
\end{tabular}


de Beaumont (1981), de que a umidade promove um atraso na pirólise, devido à necessidade da madeira ser inicialmente aquecida até a completa evaporação da água contida no interior, para finalmente ocorrerem as reações pirolíticas.

No que se refere à espécie timborana, os carvões produzidos nos dois tempos de carbonização podem ter sido oriundos de resíduos contendo um teor de umidade semelhante ou muito proximo entre si. Assim, a madeira submetida a um maior tempo de carbonização sofreu um maior grau de volatilização, confirmando a tendência de menor fração de carvão no final do processo.

O rendimento gravimétrico do carvão apresentou diferença altamente significativa entre as espécies estudadas e não significativa para o tempo de carbonização (Tabela 3), sendo uma característica de fundamental importância para o conhecimento do percentual de madeira enfornada que é transformado em carvão.

A comparação de médias de rendimento em carvão (Tabela 4) indica que os carvões de maçaranduba e timborana estatisticamente não possuem diferença significativa, enquanto que o de sapucaia é diferente dos demais.

\section{PROPRIEDADES FÍSICAS DO CARVÃO VEGETAL}

\section{DENSIDADE A GRANEL}

As médias de densidade a granel do carvão encontram-se na Tabela 2. Foi constatado que os carvôes de maçaranduba e sapucaia apresentaram-se bem mais pesados do que o de timborana, validando a lógica de que madeira pesada, normalmente, gera carvão pesado. Isso está de acordo com os resultados de Mendes et al. (1982), os quais mostram que quanto maior a densidade da madeira maior é o peso do carvão.

No que se refere ao tempo de carbonização, observou-se que essa variável da conversão pirolítica age muito pouco sobre a

Tabela 3 - Valor F obtido na análise de variância do rendimento gravimétrico, densidade a granel, densidade aparente, poder calorífico, materiais voláteis, teor de cinza, carbono fixo e friabilidade do carvão de três espécies madeireiras carbonizadas em 7 e 10 dias. Cikel Brasil Verde S.A./ Universidade Federal Rural da Amazônia.

\begin{tabular}{|c|c|c|c|c|}
\hline \multicolumn{5}{|c|}{$F$} \\
\hline & Tratamento & Espécie & Tempo & $\begin{array}{c}\text { Espécie } \mathrm{x} \\
\text { Tempo }\end{array}$ \\
\hline $\begin{array}{c}\text { Rendimento } \\
\text { gravimétrico (\%) }\end{array}$ & $3,58^{* *}$ & $7,48^{\star *}$ & $0,77^{\mathrm{ns}}$ & $1,08^{\text {ns }}$ \\
\hline $\begin{array}{l}\text { Densidade a granel } \\
\qquad\left(\mathrm{kg} \cdot \mathrm{m}^{-3}\right)\end{array}$ & $7,23^{* *}$ & 15,51 ** & $21,16^{\mathrm{ns}}$ & $1,48^{\text {ns }}$ \\
\hline $\begin{array}{c}\text { Densidade aparente } \\
\left(\mathrm{g}^{\left.-\mathrm{cm}^{-3}\right)}\right.\end{array}$ & 21,69 ** & $48,88^{* *}$ & $51,41^{\star *}$ & $2,64^{\text {ns }}$ \\
\hline $\begin{array}{l}\text { Poder Calorífico } \\
\left(\mathrm{kj}^{\mathrm{k}} \mathrm{kg}^{-1}\right)\end{array}$ & $2,39^{\text {ns }}$ & $3,28^{\text {ns }}$ & $1,75^{\mathrm{ns}}$ & $1,84^{\text {ns }}$ \\
\hline Materiais Voláteis (\%) & $6,97 * *$ & 3,79 * & $99,51 * *$ & $8,87^{\star *}$ \\
\hline Teor de cinzas (\%) & $30,75^{\star *}$ & $51,40^{* *}$ & $10,33^{\star *}$ & 20,31 ** \\
\hline Carbono fixo (\%) & $6,27^{* *}$ & $3,37 \mathrm{~ns}$ & $11,69 * *$ & $6,45^{\star \star}$ \\
\hline Friabilidade (\%) & $30,13^{\star *}$ & $70,78^{\star *}$ & $2,79^{\text {ns }}$ & $3,13^{\text {ns }}$ \\
\hline
\end{tabular}

F: Razão da variância; *: Significativo; **: Altamente significativo; " ns: Não significativo. densidade a granel, que expressa a relação entre o peso do carvão contido em um recipiente de $1 \mathrm{~m}^{3}$ de volume. Essa propriedade está mais relacionada com a granulometria, ou seja, maior ou menor quantidade de massa por unidade de volume ou da existência de vazios entre os pedaços de carvão contidos no recipiente.

A análise de variância indica que o fator espécie é altamente significativo sobre a densidade a granel. No que concerne ao tempo de carbonização, constatou-se que para a maçaranduba esse fator não causou qualquer efeito sobre a densidade a granel, enquanto que para a sapucaia teve um efeito negativo, causando uma diminuição de aproximadamente $6,91 \%$, e para a timborana o efeito foi positivo, havendo um acréscimo de 2,34\%. Apesar dessas variações, comprovou-se que as diferenças observadas não são estatisticamente significativas (Tabela 3).

A comparação das médias de densidade a granel sob o efeito do fator espécie indicou diferença altamente significativa entre as três médias através do teste SNK ao nível de 5\% de probabilidade (Tabela 4).

\section{DENSIDADE APARENTE DO CARVÃO}

As médias de densidade aparente do carvão produzido podem ser observadas na Tabela 2. Constata-se que carvôes de maçaranduba e sapucaia são mais pesados que o de timborana, vindo assim a confirmar que madeira densa gera carvão também denso. Essa tendência também foi observada por Numazawa (1986), o qual estudou resíduos de três espécies de densidade diferente da região de Curuá-Una/Pará, por Mendes et al. (1982) que estudaram carvão de vários eucaliptos e por Pastore et al. (1989) que estudaram 20 espécies da regiáo amazônica.

No que concerne a tempo de carbonização, constatou-se que somente a espécie sapucaia sofreu o efeito desse fator, apresentando densidade de $0,56 \mathrm{~g} \cdot \mathrm{cm}^{-3}$ para carvão obtido em sete dias de carbonização e $0,49 \mathrm{~g} \cdot \mathrm{cm}^{-3} \mathrm{em}$ de dez dias.

Os valores de densidade aparente de carvão obtidos neste estudo são muito próximos dos carvões de madeiras tropicais com densidades equivalentes encontrados em várias pesquisas como, por exemplo, em Numazawa (1986), Pastore et al. (1989) e Numazawa (2000).

Tabela 4 - Comparação de médias do rendimento gravimétrico (RG), densidade a granel (DG), densidade aparente (DA), friabilidade $(F)$ do carvão pelo teste Student Newman Keuls (5\%), de três espécies madeireiras carbonizadas, em 7 e 10 dias. Cikel Brasil Verde S.A. Universidade Federal Rural da Amazônia.

\begin{tabular}{ccccc}
\hline ESPÉCIE & $\mathbf{R G ( \% )}$ & $\mathbf{D G}\left(\mathbf{k g} \cdot \mathbf{m}^{-3}\right)$ & $\mathbf{D A}\left(\mathbf{g} \cdot \mathbf{c m}^{-3}\right)$ & $\mathbf{F}(\%)$ \\
\hline Maçaranduba & $25,52 \mathrm{a}$ & $231,1 \mathrm{a}$ & $0,53 \mathrm{a}$ & $30 \mathrm{a}$ \\
Sapucaia & $21,53 \mathrm{~b}$ & $202,7 \mathrm{~b}$ & $0.52 \mathrm{a}$ & $29 \mathrm{a}$ \\
Timborana & $27,62 \mathrm{a}$ & $178,5 \mathrm{c}$ & $0,38 \mathrm{~b}$ & $13 \mathrm{~b}$ \\
\hline
\end{tabular}

Médias seguidas da mesma letra não apresentam diferença entre si. 
A análise de densidade aparente do carvão mostrou ter ocorrido diferença significativa entre as espécies (Tabela 3). No entanto, não foi observada diferença em relação ao tempo de carbonização.

O teste de comparação de médias realizado através do método de SNK, ao nível de $5 \%$ de probabilidade (Tabela 4), indica que as espécies maçaranduba e sapucaia apresentaram densidade aparente do carvão diferente de timborana. Este resultado apresentou relação direta com a densidade da madeira, pois timborana apresentou densidade bastante inferior em relação às espécies maçaranduba e sapucaia. Esta tendência já foi observada em outros estudos como, por exemplo, em Numazawa (1986), Pastore et al. (1989) e Aquino (2003).

A relação direta existente entre os valores de densidade da madeira e densidade do carvão, conforme se observa nesse estudo, intensifica a importância da separação de resíduos por espécies, assim como a sua escolha para produção de carvão. Esse procedimento permite prever as características do carvão, mediante a avaliação da densidade de sua madeira, proporcionando que a empresa direcione sua produção conforme a necessidade do consumidor, e realize pesquisas no intuito de melhorar as características do carvão.

\section{PODER CALORÍFICO SUPERIOR DO CARVÃO}

Conforme a Tabela 2 foi observado que o poder calorífico do carvão varia entre as espécies estudadas. Para maçaranduba e timborana, o tempo de carbonização causou um decréscimo no poder calorífico da ordem de 12,63 e 5, $11 \%$, respectivamente, enquanto que para sapucaia houve um aumento de $4,48 \%$. Isto demonstra que o efeito foi mais importante para maçaranduba.

Segundo Oliveira et al. (1982), Satonaka (1982), Petroff \& Doat (1978) e Earl (1974), o poder calorífico pode variar de acordo com a composição química do carvão (teores de materiais voláteis, carbono fixo e cinzas). Os resultados obtidos nesse trabalho vêm confirmar esta argumentação, ou seja, em face à diferente composição química (ver item 3.4), os carvões apresentaram diferentes valores de poder calorífico.

Globalmente, os valores de poder calorífico do carvão de resíduos industriais são menores do que aqueles encontrados por Aquino (2003), de 28751 a $32047 \mathrm{kj} \cdot \mathrm{kg}^{-1}$, e por Numazawa (1986), de 29819 a 34891 kj.kg-1 .

A análise de variância para o poder calorífico superior do carvão não mostrou diferença significativa em função da espécie e do tempo de carbonizaçãoo (Tabela 3).

Os resultados obtidos não condizem com o esperado, pois maçaranduba e timborana tiveram maior poder calorífico na carbonização de sete dias e o esperado era que isso acontecesse no maior tempo. Existem duas possibilidades que poderiam explicar este resultado: a primeira seria um maior teor de umidade dos resíduos utilizados na carbonização de 10 dias, proporcionando assim o menor grau de volatilização; a segunda seria a execução do travamento (abafamento) do forno ter ocorrido muito cedo, fazendo com que a temperatura interna se mantivesse baixa, causando, portanto, uma menor volatilização.

\section{PROPRIEDADES QUIIMICAS}

\section{MATERIAIS VOLÁTEIS}

$\mathrm{Na}$ Tabela 2, encontram-se os valores médios de materiais voláteis contidos no carvão. Constata-se que a maçaranduba e a timborana sofreram menor grau de volatilização para carbonização em dez dias. Esse resultado não era esperado, uma vez que, quanto maior a exposição da madeira ao calor maior é o grau de volatilização. De forma que, esse resultado pode ter sido conseqüência do maior teor de umidade inicial da madeira carbonizada em 10 dias. Isto provocou um tempo maior de secagem da madeira, portanto um menor tempo efetivo de carbonização, provocando um menor grau de volatilização e, finalmente, resultando em maior quantidade de voláteis contidos no interior do carvão. Essa argumentação vem concordar com Oliveira \& Almeida (1980) e Wenzl (1970), quando mostram que o tempo de carbonização é diretamente proporcional ao grau de volatilização e vice-versa (menor taxa de aquecimento). O carvão de sapucaia apresentou uma tendência lógica, vindo, assim, concordar com os autores anteriormente citados. Esses valores encontrados estão muito próximos dos resultados encontrados por Numazawa (1986), que carbonizou resíduos de exploração florestal a $400^{\circ} \mathrm{C}$.

A análise de variância dos materiais voláteis indica diferença significativa em relação à espécie e altamente significativa em relação ao tempo e interação (Tabela 3).

Analisando a influência do tempo sobre as espécies, observouse que a timborana e a maçaranduba diferiram após sete e dez dias de carbonização, enquanto que sapucaia, tanto nos sete como nos dez dias, não apresentou diferença na porcentagem de materiais voláteis (Tabela 5). Em relação à sapucaia, o teor de materiais voláteis no carvão após sete e dez dias é coerente com aquelas observadas em laboratório, onde todos os procedimentos são controlados, ou seja, quanto maior for o tempo de carbonização menor será a quantidade de materiais voláteis contidos no carvão.

Tabela 5 - Comparação de médias do material volátil (MV), teor de cinzas (TC) e carbono fixo (CF) do carvão pelo teste Student Newman Keuls (5\%), de três espécies madeireiras carbonizadas, em sete e dez dias. Cikel Brasil Verde. S.A./ Universidade Federal Rural da Amazônia.

\begin{tabular}{ccccccc}
\hline \multirow{2}{*}{ ESPÉCIE } & \multicolumn{2}{c}{ MV } & \multicolumn{2}{c}{ TC } & \multicolumn{2}{c}{ CF } \\
\cline { 2 - 7 } & 7 dias & 10 dias & 7 dias & 10 dias & 7 dias & 10 dias \\
\hline Maçaranduba & $24,71 \mathrm{~b}$ & $27,93 \mathrm{a}$ & $0,8 \mathrm{~b}$ & $0,7 \mathrm{c}$ & $74,49 \mathrm{a}$ & $71,35 \mathrm{a}$ \\
Sapucaia & $26,00 \mathrm{a}$ & $23,94 \mathrm{a}$ & $1,3 \mathrm{a}$ & $2,5 \mathrm{a}$ & $72,66 \mathrm{a}$ & $73,58 \mathrm{a}$ \\
Timborana & $24,44 \mathrm{~b}$ & $31,47 \mathrm{a}$ & $1,5 \mathrm{a}$ & $1,4 \mathrm{~b}$ & $74,02 \mathrm{a}$ & $68,29 \mathrm{~b}$ \\
\hline Médias seguidas da mesma letra não apresentam diferença entre si.
\end{tabular}


Nas condições reais de fabricação de carvão em forno "Rabo Quente" é muito difícil de se conduzir uma carbonização com temperatura homogênea no interior do forno, o que provoca, conseqüentemente, a desigualdade nas características do carvão.

\section{TEOR DE CINZAS}

As médias do teor de cinzas encontram-se na Tabela 2. Verifica-se que os valores mostrados estão dentro do limite dos carvôes de madeiras tropicais encontrados por outros pesquisadores tais como Aquino (2003) e Numazawa (1986), que encontraram valores variando de 0,43 a $1,76 \%$, exceto para o carvão de sapucaia produzido em 10 dias de carbonização que foi de $2,5 \%$.

Observou-se que os fatores espécie, tempo de carbonização e as interaçōes causaram diferenças altamente significativas no teor de cinzas (Tabela 3). Acredita-se que este resultado pode ser intrínseco à espécie, pois conforme Collet (1956), o teor de cinzas após carbonização depende da quantidade de compostos inorgânicos presentes na madeira. Se isto condisser com a realidade, sapucaia e timborana não podem ser consideradas adequadas para produzir carvão para ser utilizado na siderurgia.

Nos sete dias de carbonização, maçaranduba apresentou diferença entre sapucaia e timborana, que por sua vez não diferiram entre si. Após dez dias de carbonização todas as espécies tiveram comportamento diferenciado, com sapucaia apresentando o maior teor de cinzas (Tabela 5).

\section{TEOR DE CARBONO FIXO}

As médias de teor de carbono fixo estão demonstradas na Tabela 2. Observa-se que, exceto para a espécie sapucaia que apresentou maior teor de carbono fixo para carvão produzido em dez dias, os demais não tiveram esta tendência. Esse comportamento já tinha sido verificado com teor de materiais voláteis que apresentou tendência contrária ao de teor de carbono fixo. Os valores encontrados são comparáveis com os de Numazawa (1986) para carbonização a $400^{\circ} \mathrm{C}$ com madeira de Manilkara huberi (Ducke) Standl (maçaranduba), Goupia glabra Aubl. (cupiúba) e Dinizia excelsa Ducke (angelim-pedra) que variou de 68,17 a 70,67\%, e Aquino (2003) com madeira de Manilkara huberi (Ducke) Standl (maçaranduba), Hymenolobium sp. (angelim) e Hymenaea courbaril L. (jatobá) que variou de 67,15 a $75,24 \%$. Esses dois autores trabalharam em escala laboratorial.

A análise de variância indicou que o fator espécie não causou uma variação que estatisticamente seja significativa sobre o teor de carbono fixo. No entanto, causou diferença altamente significativa com o tempo de carbonização e com a interação (Tabela 3).

Observou-se que timborana, após dez dias de carbonização apresentou comportamento bastante diferenciado das demais espécies aos sete e dez dias. Talvez, a mais baixa densidade desta madeira pode ter conduzido a este resultado (Tabela 5).

\section{PROPRIEDADE MECÂNICA (FRIABILIDADE)}

A friabilidade não apresentou uma tendência característica para que fosse possível inferir sobre um padrão. A maçaranduba, que apresenta densidade da madeira semelhante à sapucaia, aumentou a produção de finos com o tempo de carbonização, enquanto que a sapucaia reduziu. Timborana apresentou a mesma tendência da maçaranduba, porém uma friabilidade bastante inferior, o que certamente é uma característica intrínseca da espécie (Tabela 2).

Segundo a classificação do Centre Tecnique Forestier Tropical - CTFT (1972), o carvão de timborana é pouco a medianamente friável nas duas condições de carbonização (sete e dez dias) e os demais variam de bastante a muito friável (Tabela 6).

A friabilidade apresentou diferença significativa somente para espécies e não significativa para tempo e interação (tempo x espécie), conforme se observa na Tabela 3.

Analisando isoladamente a espécie do tempo de carbonização, é possível observar na Tabela 4 que, realmente, foi timborana a responsável pela diferença significativa das espécies estudadas.

Não se pode deixar de mencionar o fato de que existe diferença nos resultados provenientes do carvão produzido em laboratório (fatores controlados) em relação àquele produzido nas carvoarias, onde não é possível controlar algumas variáveis. Esse fato, dificultou comparaçóes com outros trabalhos, mas serviu para alertar que comparações devem ser feitas com restriçōes.

Num contexto geral, a partir dos resultados descritos isoladamente, foi possível fazer algumas constataçōes gerais, referentes às espécies, propriedades e tempo de carbonização, das quais foram obtidas as conclusôes.

Assim, constatou-se que somente sapucaia apresentou comportamento semelhante a outras espécies pesquisadas na Amazônia e demais regiōes para as propriedades: densidade a granel, densidade aparente, poder calorífico, materiais voláteis, teor de cinzas e teor de carbono fixo, o que não significa considerála como a melhor espécie para produção de carvão. Da mesma forma observou-se que maçaranduba e timborana não são espécies

Tabela 6 - Caracterização do carvão quanto a friabilidade.

\begin{tabular}{cc}
\hline Classificação do carvão & Perda em forma de partículas \\
\hline Muito friável & Superior a $30 \%$ \\
\hline Bastante friável & 25 a $29 \%$ \\
Medianamente friável & 15 a $24 \%$ \\
Pouco friável & 10 a $14 \%$ \\
Muito pouco friável & Inferior a $10 \%$ \\
\hline
\end{tabular}

Fonte: CTFT (Centre Technique Forestier Tropical) 
que condizem com padrôes observados em laboratório.

Se as variáveis consideradas, na produção de carvão, fosse densidade a granel, densidade aparente e teor de cinzas, a espécie maçaranduba seria a mais adequada. Se as propriedades analisadas fossem densidade aparente e teor de carbono fixam escolher-seia a sapucaia. Timborana apresentou-se como a melhor espécie em relação ao rendimento gravimétrico e friabilidade.

Neste contexto, não se pode determinar a melhor espécie considerando todas as propriedades, porém, sabe-se que o resíduo da madeira na indústria existe e que deve ser aproveitado com o objetivo de trazer maior retorno econômico para a empresa. Dessa forma, deve-se, então, avaliar a espécie, abrangendo não todas as características, mas unindo características prioritárias, conforme a necessidade do consumidor.

No caso do carvão para siderurgia, as principais características e propriedades a serem avaliadas consistem em maior quantidade de carbono fixo e menor teor de cinzas, conseqüentemente, maçaranduba preenche estes requisitos, pois apesar de apresentar menos carbono fixo $(72,92 \%)$, em relação à sapucaia $(73,12$ $\%)$, apresentou bem menor teor de cinzas.

No caso de carvão para geração de energia, a sapucaia apresentou maiores valores de densidade aparente e poder calorífico, que são características de fundamental importância para as empresas termoelétricas e indústrias químicas.

No entanto, em relação ao tempo de carbonização, a espécie sapucaia, explicitamente, mostrou que apresenta característica para carbonização somente em sete dias, considerando que várias das propriedades (densidade a granel, densidade aparente, poder calorífico e carbono fixo) mostraram resultados inferiores na carbonização em dez dias.

A timborana apresentou a mais baixa friabilidade (13,5\%), característica muito importante, quando se refere ao transporte à longa distância, ao contrário de maçaranduba e sapucaia que apresentaram valores bastante elevados, restringindo então ao transporte.

Considerando a produção anual das espécies na área de exploração e na indústria, observou-se que a maçaranduba apresentou o maior potencial energético em relação à sapucaia e timborana, pois dos $23348 \mathrm{~m}^{3}$.ano ${ }^{-1}$, que são explorados da maçaranduba, aproximadamente, $11674 \mathrm{~m}^{3}$. nno $^{-1}$ referem-se ao resíduo utilizado para a produção de carvão. A sapucaia e a timborana apresentaram bem menor potencialidade, considerando que a empresa disponibiliza em média de 668,5e $516,5 \mathrm{~m}^{3}$.ano ${ }^{-1}$ de resíduo, respectivamente.

\section{CONCLUSÕES}

Timborana foi a espécie que respondeu com maior rendimento gravimétrico de carvão em função do tempo de carbonização.
A madeira de densidade elevada como a maçaranduba e sapucaia, garante a produção de carvão denso.

A maçaranduba e a sapucaia são as espécies que tem maior potencial energético com maior quantidade de energia por unidade de massa.

As características químicas do carvão de maçaranduba e timborana não seguiram uma tendência lógica em função do tempo de carbonização.

Para as condições e época que foi desenvolvido o trabalho, a carbonização em sete dias propicia obter carvão de melhor qualidade.

Entre as espécies estudadas, a timborana é a mais qualificada para transporte à longa distância devido à baixa friabilidade do carvão.

A espécie foi o fator que mais influenciou nas características do carvão. $\mathrm{O}$ tempo de carbonização causou influência sobretudo nas características químicas do carvão.

\section{BIBLIOGRAFIA CITADA}

Aquino, J.N. 2003. Caracterização do carvão de resíduos de processamento primário da madeira e sua potencialidade energética. Universidade Federal Rural da Amazônia. Belém, PA. 81pp.

ASTM - American Society for Testing and Material. 2005. Standard Test Method for Gross Calorific Value of Coal and Coke. Book of Standards, V. 05.06. ASTM International.

Beaumont, O. 1981. Pyrolyse extractive du bois. Thèse de DocteurIngénieur, ENSM. 160pp.

Benzo, G.; Luengo, C.A. 1998. Biomassa com potencial energético adicional aos combustíveis fósseis.. In: Congresso brasileiro de planejamento energético, 3, São Paulo. Anais. P.133-137.

CTFT - Centre Technique Forestier Tropical. 1972. Resultados de 20 estudos dos produtos da destilação das madeiras amazônicas. CTFT. 32pp.

Collet, F. 1956. Estudos comparativos, em escala laboratorial de diversas madeiras utilizadas na fabricação de carvão vegetal. São Paulo. $A B M, 12$ (42): 5-14.

Earl, D.E. 1974. Charcoal. Food and Agriculture Organization of the United Nations. Roma. 97pp.

Harris, J.M. 1965. The heritability of wood density. International Union of Forest Research Organization. Meeting, secttion 41, Melbourne. Proceedings. Melbourne, IUFRO. V.2, 14p.

IBDF. 1988. Madeiras da Amazônia - características e utilização. Estação Experimental de Curuá-Una. vol. II. Brasilia, IBDF/LPF. 236P.

Mendes, M.G.; Gomes, P.A.; Almeida, M.R. 1982. Propriedades do carvão vegetal. In: CETEC. Produção e Utilização de Carvão Vegetal. Belo Horizonte. P.75-89 (SPT-008).

Nogueira, L.A.H.; Lora, E.E.S. 2003. Dendroenergia: fundamentose aplicaçôes. Rio de Janeiro: Interciência, 2.ed. 199pp. 
Numazawa, S. 1986. Aproveitamento de residuos de exploração florestal em Curua-Una/Pa, para produção de carvão vegetal. Dissertação de Mestrado, Universidade Federal do Paraná, Curitiba, PR. 126pp.

Numazawa, S. Contribution à l'etude de la pyrolyse lente du bois sous pression - Determination de paramètres optima de procede et dês caractéristiques dês produits obtens. 2000. Tese Doutorado. Université de Techlogie de Compiègne. 230pp.

Oliveira. E.; Vital. R.B.; Valente. F.; Gomide. L.J. 1989. Efeito da qualidade da madeira sobre o rendimento e qualidade do carvão de Eucalyptus grandis. Revista Arvore, 13(1): 85-97.

Oliveira. J.B.; Almeida, M.R. 1980. Avaliação de carvão vegetal. In: CETEC. Uso da madeira para fins energéticos. Belo Horizonte. P.43-53 (SPT-001).

Oliveira. J.B.; Vivacqua Filho, A.; Mendes, M.G.; Gomes, P.A. 1982. Produção de carvão vegetal - aspectos técnicos. In: CETEC. Produção e Utilização de Carvão Vegetal. Belo Horizonte. P.5972 (SPT-008)

Pastore. M.C.T.; Okino. A.Y.E.; Pastore. Jr. F. 1989. Carbonização de Madeiras da Amazonia Parte 1: Floresta Nacional do Tapajós. Brasília. IBAMA/DIRPED/LPF. 12p.(Série Técnica nº12).

Petroff, G.; Doat, J. 1978. Pirolyse des bois tropicaux - Influence de la composition chimique de bois sur les produits de distillation. Revue Bois et Forêt des Tropiques. Nojent sur Marne/France. Centre Techinique Forestier Tropical - CTFT. 177:51-64.

Satonaka, S. 1982. Carbonization and Gaseification of Wood. Energy from forest biomass. Ed. By W. Ramsay Smith College of Forests resources. University of Washington, Scattle. Washington. XVIIIUFRO World Congress Energy Group Proceeding. Academic Press. P.147-154.

Souza, M.H.; Magliano, M.M.; Camargo, J.A.A. 1997. Madeiras tropicais brasileiras. Brasilia. IBAMA/LPF. 152p.

SUDAM/EMBRAPA. SNLCS. 1993. Estudos climáticos do estado do Pará, classificação (Köppen) e deficiência hídrica (Thorntwaite, Mather). Belém: SUDAM/EMBRAPA. p.26.

Vale, A.T.; Moura, V.P.G.; Martins, I.S.; Pereira, F.S. 1997. Influência da gamose e da procedência de Eucalyptus grandis W. Hill ex Maidem no rendimento da carbonização e na qualidade do carvão vegetal. Revista Árvore, 21(2): 253-258.

Veloso, H.P.; Rangel Filho, A.L.R.; Lima, J.C.A. 1991. Classificação da vegetação brasileira adaptada a um sistema universal. Departamento de Recursos Naturais e Estudos Ambientais / IBGE, Rio de Janeiro.

Watrin, O. dos S.; Rocha, A.M.A. 1991. Levantamento da vegetação natural e do uso da terra no município de Paragominas (PA) utilizando imagens TM/LANDSAT. Belém: Embrapa - CPATU. 40p. (Embrapa - CPATU. Boletim de Pesquisa, 124).

Wenzl, H.F.J. 1970. The chemical technology of wood. New York. Academic Press. 692pp.

Recebido em 04/06/04

Aceito em 30/01/07 